\title{
Die Darstellung und Funktion von Angst im Märchen Schneewittchen
}

\section{Die Gebrüder Grimm und Walt Disney im Vergleich}

Abstract: In diesem Aufsatz werden verschiedene Versionen des klassischen Grimm-Märchens „Schneewittchen“ miteinander verglichen, wobei das Hauptaugenmerk auf der sprachlichen Konstruktion und Darstellung der Emotion Angst liegt. Die beiden Grimm-Fassungen von 1812 und 1850 erreichen ihre pädagogische Wirkung vor allem dadurch, dass sie ihre Charaktere mit angsteinflößenden Situationen konfrontieren und die sich daraus ergebenden angstvollen Reaktionen ausführlich beschreiben. Um solch beängstigende Situationen zu kreieren, greifen die Grimm-Fassungen auf Motive zurück, die für das Phänomen der Angst typisch sind: Verlassen-werden, unzuverlässige Elternfiguren, Altern und Tod und die zerstörende Kraft der Natur. Die ängstlichen Reaktionen der Charaktere werden üblicherweise durch den Gebrauch von Metonymien und Metaphern im Bereich körperlicher Reaktionen - wie beispielsweise Erblassen, erhöhter Herzschlag oder die Unfähigkeit $\mathrm{zu}$ sprechen, $\mathrm{zu}$ denken und sich $\mathrm{zu}$ bewegen - ausgedrückt. Besonders Kövecses‘ Schrift Emotion Concepts sowie der sich teilweise darauf beziehende Artikel Schiss und Espenlaub: Idiome der Angst von Dobrovol'skij liefern bei der Analyse dieser Angst-Stellen interessante Erkenntnisse. Sowohl die Entwicklung der bösen Stiefmutter zu einer zunehmend furchteinflößenderen Gegnerin und einem abschreckenden Beispiel für den Leser, als auch Schneewittchens Anfälligkeit für menschliche Fehler, welche die Leser-Identifikation erleichtert, verstärken die erzieherische Wirkung des Märchens. Die Disney-Version von 2018 hingegen lässt einen pädagogischen Effekt vermissen, da sie Schneewittchen einseitig als idealisierte, engelsgleiche Figur präsentiert und somit eine wahre Identifikation mit ihr erschwert. Zudem wird die Königin von Beginn an als grundsätzlich böse Figur etabliert, wodurch ihr das Potential zu einer beängstigenden Entwicklung genommen wird. Durch das Auslassen zweier von drei Anschlägen der Stiefmutter auf Schneewittchen und durch den umfangreichen Gebrauch von Euphemismen geht ein Großteil der angstauslösenden sowie belehrenden Wirkung des Originals verloren.

This article compares different versions of the Grimm brothers' classical fairy tale "Snow White" while focusing on how the emotion fear is constructed and depicted linguistically. The Grimm editions from 1812 and 1850 draw much of 
their educational impact from exposing the characters to frightening situations and showing their fearful reactions. In order to create such frightening situations, the tales fall back on motives typical of the phenomenon of fear: abandonment, unreliable parental figures, aging and death and the destructive forces of nature. The characters' fearful reactions are commonly expressed through the use of metonymies and metaphors related to the body, such as turning pale, experiencing an increase in heart rate or being unable to speak, think and move. The stories' pedagogical effect is reinforced by giving the evil stepmother room to develop into an increasingly terrifying opponent who serves as a warning and by allowing Snow White to make human mistakes which facilitates reader identification. The Disney version from 2018, on the other hand, lacks a sufficiently educational function for it one-sidedly presents Snow White as an idealized angel-like figure, thereby complicating true identification, while making the stepmother inherently wicked from the start. By leaving out two out of three assassination attempts on Snow White and by extensively using euphemisms, much of the original's fear-inducing as well as instructive effect is lost in the modernized version.

Die Angst als „Grunderfahrung menschlicher Existenz“ (Dinzelbacher 1993: 315) beschäftigt uns - ob nun bewusst oder unbewusst - tagtäglich. Zwar verändern sich die Ängste der Menschen, und auch unser Umgang mit diesen erfährt historisch gesehen einen Wandel (siehe Dinzelbacher 1993), doch das Bedürfnis und die Notwendigkeit, unsere Ängste in Worte zu fassen, bleibt über die Zeit hinweg erhalten.

Als Emotion ist die Angst Bestandteil unseres Erlebens und somit auch essentieller Teil unserer Interaktion mit anderen Menschen, denen wir ein spezifisches Erleben kommunikativ vermitteln möchten (vgl. Fiehler 2011: 17, 19). Wollen wir über unsere Gefühle sprechen, stehen uns dafür verschiedene sprachliche Verfahren zur Verfügung; so können wir beispielsweise auf einen bestimmten Erlebenswortschatz zurückgreifen, um unseren Ängsten in einer Konversation Ausdruck zu verleihen oder aber unsere Emotionen durch den Gebrauch spezieller sprachlicher Mittel umzuschreiben (ebd. 22f.). Für die sprachliche Konzeptualisierung der Emotion Angst spielen hierbei Idiome und konventionelle Metaphern eine zentrale Rolle, da es uns durch sie möglich ist, die sonst nicht beobachtbaren Phänomene des Geistes in der objektivierbaren Welt der physischen Reaktionen widerspiegelt zu sehen - wir konzeptualisieren Angst als Analogie zu anderen, greifbareren Bereichen (vgl. Dobrovol'skij 1995: 318, Fiehler 2011: 25). Ganz konkret bedeutet dies, dass nicht bloß die Aussage 
„Ich habe Angst“ eine akkurate sprachliche Benennung dieser Emotion darstellt, sondern dies auch viel subtiler geschehen kann, unter anderem durch den Rückgriff auf gewisse Angst-Idiome: z. B. Mir stehen die Haare zu Berge (vgl. Dobrovol'skij 1995: 328, Unterteilung verschiedener source domains).

Wir verbalisieren unsere Ängste aber nicht nur in der interpersonalen Interaktion - die Grundemotion der Angst wird auch in schriftlichen Texten auf unterschiedliche Weise kommuniziert und sprachlich konstruiert. Es sind beispielsweise gerade die verschriftlichten Erkenntnisse antiker Dichter und Philosophen oder die Analyse althochdeutscher und mittelhochdeutscher Epik (vgl. Endres 1987, Gerok-Reiter 2007), die uns Aufschluss geben können über die Angstempfindungen und -einstellungen der Menschen früherer Epochen und über die sprachliche Konstruktion derselben.

Auch heute rückt sowohl das verbale als auch das schriftliche Gespräch über die Angst zunehmend in den Fokus - laut Bähr haben Furcht und Angst wieder Konjunktur (vgl. Bähr 2013: 21), was sich in den Untersuchungen Beckers bestätigt, die Angst als eine Leitvokabel in der aktuellen Flüchtlingsdebatte identifiziert (vgl. Becker 2016: 1). Dies mag auch damit zusammenhängen, dass besonders eine solch starke Emotion wie Angst durch gewisse Diskursakteure aktiv erzeugt und verstärkt werden kann, um Diskussionen und Diskussionsteilnehmer gezielt zu beeinflussen (vgl. Becker 2016: 9). Das bedrohliche Potential der Angst, zur „Disziplinierung der Untertanen“ instrumentalisiert werden zu können, lässt sich geschichtsübergreifend beobachten (vgl. Dinzelbacher 1993: 338). Aber die Angst kann auch zu pädagogischen Zwecken ,instrumentalisiert` werden, was sich besonders in der Textsorte des Märchens zeigt.

Die sprachliche Darstellung der Emotion Angst anhand von Märchentexten zu untersuchen, ist deshalb interessant, weil diese Textgattung heutzutage sowohl den Ruf hat, speziell auf Kinder ausgerichtet zu sein, als auch für ihr inhärentes Angstpotential bekannt ist, welches sich beispielsweise in Form von grausamen Strafen für Boshaftigkeit und Ungehorsam äußert. In diesem Zusammenhang gab und gibt es auch immer wieder Auseinandersetzungen zwischen Märchenbefürwortern, die die Konfrontation von Ängsten als pädagogisch wertvoll betrachten, und Märchengegnern, die das Angstpotential des Märchens als für Kinder abträglich, gar schädlich empfinden. Allein dieser anhaltende Konflikt spricht für eine Analyse der sprachlichen Darstellung der Angst im Märchen, welche auch Aufschluss geben kann über die Funktionen dieser Angstdarstellung und deren Wirkung auf die Rezipierenden. Deshalb soll im Folgenden eine Gegenüberstellung der Grimm'schen „Schneewittchen“-Ausgaben von 1812 und 1850 und einer modernisierten, an der Verfilmung orientier- 
ten Märchenversion aus Disneys „Das große goldene Buch der Prinzessinnen“ von 2018 stattfinden.

\section{Die Angst als Grundelement des Märchens}

Vor bereits über zweihundert Jahren (1812) erschien mit der ersten Ausgabe der „Kinder- und Hausmärchen“ der Gebrüder Grimm die erste verschriftlichte Sammlung der zuvor bloß mündlich weitergetragenen Volksmärchen, welche sich schon damals zu einem der meistgelesenen Bücher innerhalb des deutschen Sprachgebiets entwickelte (vgl. Maier 1987: 66-67). Auch heutzutage scheint die Popularität des Märchens nicht abgenommen zu haben: In Buchläden findet sich stets eine speziell für Märchen eingerichtete Sektion, an deutschen Schulen ist die Lektüre von Märchen - besonders in der 5. und 6. Klasse - länderübergreifend im Lehrplan verankert und nicht zuletzt verdankt die Textgattung Märchen ihre Beliebtheit auch den modernen Disney-Verfilmungen der letzten Jahrzehnte.

Oftmals werden die Verbreitung und das Ansehen des Märchens damit in Verbindung gebracht, dass es uns ein „Welterleben“ präsentiert, dass es „wesentliche Elemente und Grundzustände des menschlichen Seins widerspiegelt“ und sein Zuständigkeitsbereich somit nicht auf eine besondere Epoche oder ein bestimmtes Volk reduziert ist, sondern die menschliche Existenz überhaupt betrifft (vgl. ebd. 80-81). Somit ist es nicht verwunderlich, dass auch die Angst als zeitloses und in allen Kulturen vorkommendes Grundgefühl des menschlichen Lebens (vgl. Götze 1984: Vorwort) nicht bloß Einzug in das Märchen gefunden hat, sondern einen Teil der „endlichen Gruppe von Elementen“ (Braun 1985: 95) bildet, die das Märchengeschehen definieren. Als solches berührt die Angst sowohl die in der Geschichte vorkommenden Figuren, als auch die Rezipierenden, der sich mit dem Helden identifiziert, mit ihm leidet und Gefahren besteht und letztendlich auch ein Stück Angst mit ihm bewältigt (vgl. Strehlow 1985: 155).

Befürworter des pädagogischen Einsatzes von Märchen betrachten diese deshalb als Angebot von Konfliktlösemustern und Bewältigungsstrategien bzw. als Modelle der Lebensbewältigung (vgl. Horn 1990: 159-160). Die Befürworter betonen ferner die Vorrangstellung des Märchens als Kinderlektüre aufgrund seiner Tendenz, die kindlichen Nöte und ihre existentiellen Ängste nicht zu verniedlichen, sondern sie in ihrer Schwere ernst zu nehmen, unmittelbar auszusprechen und für das Kind verständliche Lösungen anzubieten (vgl. Bettelheim 1977: 10, 15), die nicht bloß in der Handlung verankert sind, sondern sich 
auch in Form von Projektionsmöglichkeiten der Angst anbieten, indem für sie ein Bild geschaffen wird (vgl. Kaiste 2005: 185). Es sind häufig Hexen, Drachen und andere Schreckensgestalten, die das Böse, Unerklärliche, Unberechenbare - die Angst des Kindes - versinnbildlichen (vgl. Trescher 1985: 55) und das Märchen ist dem kindlichen Geist gerade deshalb willkommen, da in ihm „das Magisch-Wunderbare einen so selbstverständlichen Platz einnimmt wie in der Psyche des Kindes“ (Maier 1987: 85). Es kann auf diese Weise zum Reifungsprozess des Kindes beitragen, indem es seine Trennungs- und Schuldängste, seine Regressionen zu überwinden hilft (vgl. Horn 1990: 163).

Auf der anderen Seite gab und gibt es auch zahlreiche Gegner des Gebrauchs von Märchen in Zusammenhang mit Kindern. Bereits die Urfassung der Grimm‘schen „Kinder- und Hausmärchen“ war heftiger Kritik ausgesetzt, da Eltern und Erzieher die inhaltlichen Grausamkeiten vieler Märchen ablehnten und diese aufgrund ihres Angstpotentials als unangemessen für Kinder empfanden (vgl. Kaiste 2005: 34). Tatsächlich werden im Grimm'schen Märchen „[Augen] ausgestochen, Menschen in vier Stücke zerrissen, gefressen, verbrannt, ertränkt, verprügelt, gehängt, gestochen und gezwickt. Eine ganze Parade von Grausamkeiten wird dem Kind vorgeführt“ (Gutter 1968: 16). Die Empörung über so geartete Inhalte und die Forderung kindgerechter Textbearbeitung führte schon zu Grimms Zeiten zu einer „Reinigung“ der Texte (vgl. Kaiste 2005: 20f.). In den Augen der Befürworter sind solche Beschönigungen jedoch fatal:

Die meisten Kinder begegnen dem Märchen lediglich in verniedlichten, vereinfachten Versionen, die den Sinn entstellen und eine tiefere Wirkung unmöglich machen - in Filmund Fernsehbearbeitungen, in denen die Märchen zu bedeutungsloser Unterhaltung herabsinken. (Bettelheim 1977: 28)

Überdies werden solche „Zensuren“ als sinnlos abgetan, da grausame Vorgänge in den Märchen zwar genannt, niemals aber detailreich und blutig, sondern durchgehend „entwirklicht“ beschrieben werden und deshalb das Kind nicht nachhaltig beeindrucken (vgl. Kaiste 2005: 35). Die Frage, ob Märchen für Kinder geeignet sind oder nicht, soll hier jedoch nicht beantwortet werden - Jacob Grimm jedenfalls betrachtete seine Märchen als nicht eigentlich für Kinder erfunden und geschrieben, unterstützte aber ausdrücklich ihren lehrreichen Effekt und ihre eindrucksvolle Wirkung auf diese (vgl. ebd. 39).

Trotz und vielleicht gerade wegen seiner Beschäftigung mit dem „Urphänomen“ Angst (vgl. Dinzelbacher 1993: 337) hat sich das Märchen bis in die heutige Zeit durchgesetzt - wenn auch manchmal in veränderter Form: 
Far from being comfortably fixed points of cultural reference, fairy tales are in fact shifting, evanescent, subject to almost as many reversals of emphasis and periodic recyclings as the fashion industry. (Crago 2008: 163)

Die erste Zeichentrick-Verfilmung des Märchens „Schneewittchen“ (1937) durch Disney brachte wohl einen solchen bedeutungsvollen Wahrnehmungswechsel für viele Kinder, möglicherweise für alle darauffolgenden Generationen, mit sich und leitete einen Fokus auf Heldinnen und Prinzessinnen und einen Trend in Richtung Idealisierung ein (vgl. ebd. 171). Erstaunlicherweise zählt aber auch „Schneewittchen“ zu jenen Gräuelmärchen, die von Kritikern aufgrund ihrer Grausamkeitsdarstellung wiederholt angeklagt wurden (vgl. Gutter 1968: 17). Der vorliegende Beitrag soll die Frage beantworten, wie sich die Grimm'sche „Schneewittchen“-Version bezüglich der Angstdarstellung im Vergleich zu ihrem Disney-Gegenstück verhält.

\section{Die Versionen des Schneewittchen-Märchens im Vergleich}

\subsection{Familienkonstellation}

Ein grundlegender Unterschied aller drei Versionen des Märchens zeigt sich bereits in der Darstellung der Ausgangssituation: Zunächst gleichen sich beide Grimm-Versionen noch dahingehend, dass die Geburt und das Aussehen Schneewittchens durch die Erfüllung des Herzenswunsches der Mutter erklärt wird, ausgelöst durch einen Nadelstich in den Finger und durch den Anblick von drei Blutstropfen im weißen Schnee. Der Nadelstich und die drei Tropfen Blut lassen sich hier möglicherweise schon als Vorausdeutung auf die Gefahren - besonders die drei Konfrontationen mit der Königin - interpretieren, die Schneewittchen im Verlauf der Geschichte zu bestehen hat. Diese Ausgangslage fehlt in der Disney-Version ganz - sie steigt stattdessen unmittelbar mit einer Beschreibung der Königin als Gegenspielerin Schneewittchens ein.

Hier weichen die drei Versionen nun in einer Art und Weise voneinander ab, die die Angstdarstellung und -interpretation im Zusammenhang mit der Königin erheblich beeinflusst ${ }^{1}$ :

1 Aus Rölleke 1986 wird fortan die 1812er Version von Schneewittchen zitiert, aus Grimm 2000 die 1850er Version. 
Die Königin war die schönste im ganzen Land, und gar stolz auf ihre Schönheit. ${ }^{2}$ (Rölleke 1986: 245) [hier und im Folgenden meine Kursiv-Schreibung, L.K.]

Nachdem das Kind geboren war, starb die Königin. Ungefähr ein Jahr später nahm sich der König eine andere Gemahlin. Es war eine schöne Frau, aber sie war stolz und übermütig, und konnte nicht leiden, wenn sie von jemand anderem an Schönheit übertroffen wurde. (Grimm 2000: 235)

[...] da regierte eine schöne, aber grausame Königin. [...] Die Königin war sehr stolz auf sich und ihre Zauberkräfte. Doch noch viel stolzer war sie auf ihr schönes Aussehen. [...] Nach dem Tod von Schneewittchens Vater hatte die Königin das Mädchen nur noch wie eine Dienstmagd behandelt. (Disney 2018: 10, 13)

In der ältesten Version ist noch nicht die Rede von der allbekannten bösen Stiefmutter - stattdessen wird die Mutter selbst, deren Herzenswunsch es war, eine Tochter $\mathrm{zu}$ bekommen, aufgrund ihres Stolzes und ihrer Eifersucht zur Gegenspielerin Schneewittchens. Diese Ausgangssituation ist mit besonderem Angstpotential verbunden: Die eigene Mutter als fürsorgliche, ,allesspendende Beschützerin,“ deren Aufgabe darin besteht, das Überleben ihres Kindes zu sichern, verwandelt sich in das genaue Gegenteil; indem sie sich gegen ihr Kind wendet, steht dessen Leben selbst auf dem Spiel (vgl. Bettelheim 1977: 67, 195). Schneewittchens Vater bleibt in der Geschichte unerwähnt, wobei jedoch von seiner Anwesenheit auszugehen ist, da im Märchen nicht selten eine ohnmächtige, schwache Vaterfigur präsentiert wird, die unfähig dazu ist, ihre Kinder vor Gefahren der Außenwelt oder auch eigenen Charakterschwächen zu schützen (vgl. ebd.: 195). Somit wird Schneewittchen den Rezipierenden hier in einer Situation präsentiert, in der sie von keinem ihrer Elternteile Unterstützung, Geborgenheit oder Schutz erwarten kann, sondern vielmehr der Grausamkeit der eigenen Mutter hilflos ausgeliefert ist.

In der Grimm'schen Version von 1850 findet sich nun die klassische Aufspaltung in eine liebevolle Mutter und eine ablehnende Stiefmutter. Das gute Bild der eigentlichen Mutter bleibt somit unangetastet, und die hasserfüllten Gefühle der Stiefmutter gegenüber Schneewittchen lassen sich so vielleicht leichter nachvollziehen (vgl. ebd.: 67). Dennoch erweist sich auch diese Ausgangslage als angsteinflößend: Sowohl Schneewittchen, als auch die Rezipierenden werden hier mit einer grundlegenden menschlichen Not konfrontiert dem Tod eines Elternteils - welcher quälende Probleme für das alleingelassene

2 Sämtliche Änderungen an dem Grimm'schen Originaltext durch beispielsweise kursiv markierte Einschaltungen des Herausgebers und durch eckige Klammern markierte Streichungen werden hier nicht berücksichtigt, um Verständnisschwierigkeiten zu vermeiden. 
Kind aufwirft (vgl. ebd.: 13). Die „Angst, verlassen zu werden und die Liebe eines hochwertigen Objekts einzubüßen“ gehört für Dettmering (1984: 160) zu einer der grundlegenden Varianten von Märchenängsten, die sich bei seiner Analyse der Grimm-Werke ergeben haben. So wird hier zwar die eigene Mutter nicht zur Feindin, jedoch wird das Allein-Gelassen-Werden und Ausgeliefertsein Schneewittchens durch den Tod der guten Mutter zusätzlich betont, während der Vater wiederum passiv bleibt und keine Unterstützung bietet.

Die Disney-Variante geht auf die Mutter Schneewittchens nicht ein, ihr Tod bleibt unerwähnt und ihre vormalige Anwesenheit wird bloß dadurch impliziert, dass Schneewittchen als Stieftochter der Königin bezeichnet wird. Tatsächlich kommt das Wort Mutter in keiner Form in der Geschichte vor: Auch die Königin trägt niemals den Titel einer Stiefmutter. Die Disney-Version scheint die für die Handlung einstmals so wichtige Rolle der Mutterschaft herunterzuspielen (vgl. Whitley 2012: 19), um sie erst gar nicht mit der Gegenspielerin Schneewittchens in Verbindung $\mathrm{zu}$ bringen. Im gleichen Zuge werden somit auch die menschlichen Züge der Königin selbst heruntergespielt - die Geschichte beginnt mit einer bereits als grausam und über Schneewittchen dominierend etablierten Feindfigur, sie setzt sie geradezu voraus (vgl. ebd.). Somit bleibt aber auch viel der beängstigenden Wirkung aus, welche die Grimm-Versionen hervorrufen, beispielsweise durch die Andeutung, dass sich die eigene Mutter zur Feindin entwickeln kann bzw. dass auf die dauerhafte Fürsorge seitens der guten Mutter nicht immer Verlass ist. Disneys Abwendung von solch destruktiven Familientendenzen zeigt sich weiterhin, indem sich die mangelnde väterliche Unterstützung Schneewittchens durch dessen Tod erklärt. So wird zwar auch hier der Verlust eines Elternteils ausgesprochen, allerdings zum Zwecke der Aufwertung der Familiensituation: Dass die Königin Schneewittchen erst nach dem Tode des Vaters zur Magd degradiert, impliziert die schützenden Qualitäten, die ihr Vater vor seinem Tod gewiss hatte.

\subsection{Konfliktkonstruktion}

Für Märchen ist es typisch, dass es gleich zu Beginn zu einer unmittelbar erfassbaren Konfliktsituation kommt, die häufig angstauslösende Situationen der Kindheit widerspiegelt und anzeigt, dass hier „elementar menschliche [...] Beziehungskonflikt[e] zwischen Kindern und Eltern ausgespielt“ werden (vgl. Scherf 1990: 170). Der Konflikt in diesem Märchen ergibt sich zunächst hauptsächlich aus den Charaktereigenschaften der Königin.

In den Grimm-Versionen wird an ausführlicher Beschreibung der Königin gespart, sie ist, wie oben gezeigt, neben ihrer Schönheit, „stolz“ bzw. „stolz und 
übermütig“ und mehr gibt es über sie zunächst nicht zu sagen. So ist auch ihr eigentliches Verhältnis zu Schneewittchen unklar, wobei zu Beginn von keinerlei Aversionen gesprochen wird - zumal der sehnliche Wunsch einer Tochter in der ältesten Variante sogar für besondere Zuneigung sprechen könnte. In der Disney-Version hingegen wird, wie angesprochen, die außerordentliche Boshaftigkeit der Königin gleich zu Beginn festgelegt:

[...] da regierte eine schöne, aber grausame Königin. Diese Königin verstand sich auf die Kunst der Hexerei. Sie missbrauchte ihre Macht jedoch, um mithilfe von Angst und Schrecken über ihre Untertanen zu herrschen. Die Königin war sehr stolz auf sich und ihre Zauberkräfte. Doch noch viel stolzer war sie auf ihr schönes Aussehen. (Disney 2018: 10)

Bevor überhaupt Stolz zur Sprache kommt, werden der Disney-Königin bereits Grausamkeit, Hexerei, Machtmissbrauch und Schreckensherrschaft unterstellt. Sie wird so durchaus unmittelbar zu einer angsteinflößenden Figur aufgebaut und sogar mit Hexenkunst und Teufelswerk in Verbindung gebracht. Diese ausführliche Beschreibung dient hauptsächlich der „Polarisation“, also der Kennzeichnung einer Person durch den schroffen Gegensatz zu einer anderen Person - die Königin tritt hier als Extrem auf, welches dem Bereich des Bösen zugeordnet ist und so im starken Kontrast zum Schneewittchen steht, das für den Bereich des Guten eintritt (vgl. Maier 1987: 78). Auch bei den Brüdern Grimm findet eine solche Polarisation statt. Diese ist allerdings in der Charakterisierung beider Personen wesentlich einfacher gehalten und lässt zumindest etwas Raum für eine Entwicklung der Figuren, was letztendlich für die Rezipierenden mehr Spannung, Angstpotential und außerdem die Möglichkeit einer lehrreichen Erfahrung mit sich bringt.

Der eigentliche Fehler der Königin, aus welchem sich das Konfliktpotential letztlich ergibt, zeigt sich in ihrem Umgang mit dem Spiegel: „Der Spiegel der Königin ist ein Instrument, welches sie allwissend macht“ (Strehlow 1985: 121). Somit ist er Ausdruck ihrer Macht, gleichzeitig spiegelt er aber auch ihre größte Verletzlichkeit und Angst wider:

Sie hatte auch einen Spiegel, vor den trat sie alle Morgen und fragte: „Spieglein, Spieglein an der Wand, wer ist die Schönste im ganzen Land?“ da sprach der Spiegel allzeit: „Ihr, Frau Königin, seyd die Schönste Frau im Land.“ Und da wußte sie gewiß, daß niemand schöner auf der Welt war. (Rölleke 1986: 245)

[...] und konnte es nicht leiden, wenn sie von jemandem anderen an Schönheit übertroffen wurde. Sie hatte einen wunderbaren Spiegel: Wenn sie davor trat, sich in ihm betrachtete und dabei sprach: „Spieglein, Spieglein an der Wand, wer ist die Schönste im ganzen Land?“ so antwortete der Spiegel: „Frau Königin, Ihr seid die Schönste im Land.“ Dann war sie zufrieden, denn sie wusste, dass der Spiegel die Wahrheit sagte. (Grimm 2000: 235) 
Die Königin lächelte niemals - außer wenn ihr magischer Spiegel ihr die ersehnte Antwort auf diese Frage gab: „Spieglein, Spieglein an der Wand, wer ist die Schönste im ganzen Land?" Während die Königin dann in den Spiegel schaute und ihr Gesicht nach Spuren des Verfalls absuchte, verwandelte ihr Spiegelbild sich in ein grässliches Ungeheuer. Es war das Abbild des verdorbenen Herzens der Königin. Der Spiegel gab stets die gleiche Antwort: „Frau Königin, Ihr seid die Schönste im Land.“ Für einen kurzen Moment entspannte sich darauf das Gesicht der Königin und sie lächelte. (Disney 2018: 10,12)

Die größte Angst der Königin, die sie immer aufs Neue konfrontiert, indem sie vor den Spiegel tritt, ist es, in ihrer Schönheit übertroffen zu werden, gewissermaßen zu altern. Dieses Altern bzw. der Tod als Grenze unserer Existenz stellt hier wiederum eine fundamentale menschliche Angst dar (vgl. Bettelheim 1977: 13). Die Angst zeichnet sich in allen drei Versionen besonders dadurch aus, dass es für die Königin keine Ruhe und Zufriedenheit gibt, sofern sie nicht die Gewissheit hat, die Schönste in ihrem Lande zu sein. Außerordentlich beängstigend für die Königin muss sich dementsprechend der Moment der Ungewissheit darstellen, bevor der Spiegel ihr die Wahrheit enthüllt. Das abermalige Vor-denSpiegel-Treten stellt somit, besonders in den Grimm-Versionen, eine abermalige Konfrontation der Angst und, wie sich zeigen wird, eine abermalige Steigerung dieser Angst der Königin dar.

Die Disney-Version unterscheidet sich hier deutlich von den GrimmFassungen dahingehend, dass sie den Rezipierenden sich die Verdorbenheit der Königin ganz bildlich als grässliches Ungeheuer vorstellen lässt. Diese Verdorbenheit ist in dieser Fassung vorangestellt und bereits verbunden mit allerlei zu verachtenden Eigenschaften der Königin, unter welchen der Stolz auf ihre Schönheit und die Angst vor deren Verfall nur weitere Komponenten darstellen. Auch der Hass auf Schneewittchen scheint schon seit jeher vorhanden gewesen zu sein, da sie das Mädchen unmittelbar nach dem Tode ihres Vaters zur Dienstmagd machte, ohne dass dafür ein Grund angegeben wäre. Dennoch ist der konfliktauslösende Moment auch in der Disney-Version dadurch begründet, dass die Schönheit der Königin durch Schneewittchens Schönheit übertroffen wird:

Eines Tages an einem schönen Frühlingsmorgen jedoch sagte der Zauberspiegel zum Entsetzen der Königin etwas anderes: „Frau Königin, Ihr seid die Schönste hier, aber Schneewittchen ist tausendmal schöner als Ihr." Die Königin erbleichte, als ihr der Spiegel ihre Stieftochter zeigte. (Disney 2018: 12-13)

Die Angst der Königin wird hier ganz direkt deutlich, indem sie die Nachricht des Spiegels mit „Entsetzen“ aufnimmt, aber zu ihrer Versprachlichung wird auch indirekter auf den Bereich körperlicher Reaktionen zurückgegriffen - sie „erbleichte“: 
Wir können unsere Emotionen, seelischen Regungen und psychischen Reaktionen nur dann konzeptualisieren und über sie reden, wenn wir sie aus der „unsichtbaren“ und somit unfaßbaren Welt des Geistes in die „sichtbare“ und somit objektivierbare Welt der physischen Reaktionen herüberholen. Dort, wo es gilt, uns über die Regungen der Seele klar zu werden und sie zu artikulieren, greifen wir besonders oft auf Reaktionen des Körpers zurück. (Dobrovol'skij 1995: 318).

Dobrovol'skij (1995: 321) zielt in seinem Aufsatz darauf ab, Idiome der „,reinen Angst“ von solchen abzugrenzen, die neben der Angst auch auf andere starke Emotionen zutreffen können. Dementsprechend schließt er das Erblassen als symptomatischen Ausdruck für Angst aus (vgl. ebd.: 321). Für die Analyse der Schneewittchen-Versionen trifft es aber durchaus $\mathrm{zu}$, dass die grundsätzliche Angst der Königin vor dem körperlichen Verfall an andere Emotionen wie Neid, Hochmut, Eifersucht und Hass gekoppelt ist. Diese elementare Angst könnte zumindest bei den Grimm-Versionen als geradezu ausschlaggebend für das Entstehen anderer starker Emotionen betrachtet werden:

Wie die Königin den Spiegel so sprechen hörte, ward sie blaß vor Neid, und von Stund an haßte sie das Sneewittchen, und wenn sie es ansah, und gedacht, daß durch seine Schuld sie nicht mehr die schönste auf der Welt sey, kehrte sich ihr das Herz herum. Da ließ ihr der Neid keine Ruhe [...]. (Rölleke 1986: 247)

Da erschrak die Königin und wurde gelb und grün vor Neid ${ }^{3}$. Von dieser Stunde an kehrte sich ihr das Herz im Leibe herum, wenn sie Schneewittchen erblickte, so sehr hasste sie das Mädchen. Und Neid und Hochmut wuchsen wie ein Unkraut in ihrem Herzen immer höher und ließen ihr Tag und Nacht keine Ruhe mehr. (Grimm 2000: 236)

Schneewittchen ist die Schuldige daran, dass sich die größte Angst der Königin erfüllt und der Spiegel ihr nicht mehr die ersehnte, angsterlösende Antwort gibt. Hierin zeigt sich der zentrale Konflikt des Märchens. Von diesem Moment an empfindet die Königin Neid und Hass, so stark, dass sich ihr das Herz im Leibe umkehrt - eine weitere körperliche Reaktion auf das Geschehene. Viel mehr noch als bei der Disney-Version, wo die Angst vor dem Verlust ihrer Schönheit zwar ebenso vorhanden und für den Verlauf der Handlung bedeutend ist, aber anderen verwerflichen Eigenschaften wie Grausamkeit und Machtgier nebengeordnet zu sein scheint, wird besonders in der 1850er Fassung der Grimms gezeigt, wie viele der charakterlichen Übel der Königin geradezu aus dieser Angst entspringen. Bei der Disney-Version zeigt sich von Anfang an das „Abbild des

3 Gelb und grün vor Neid werden lässt sich hier durchaus weniger gut mit gleichzeitiger Angstempfindung verbinden, dafür ist aber auf die Angst der Königin ausdrücklicher verwiesen, indem sie „erschrak“. 
verdorbenen Herzens“ (Disney 2018: 12) im Spiegel, bei den Grimms wachsen „Neid und Hochmut [...] wie ein Unkraut in ihrem Herzen“ (Grimm 2000: 236) erst nachdem sich die größte Befürchtung der Königin erfüllt.

Die Angst wird in den Grimm'schen Fassungen als Charakterschwäche präsentiert, die das Herz der Königin anfällig macht für Sünden wie Hochmut, Neid und Zorn. Dies lässt sich möglicherweise vergleichen mit einigen Feststellungen, die Gerok-Reiter in ihrer Untersuchung mittelhochdeutscher Heldenepik machte. Sie ermittelte, dass Angstdarstellung in diesen Dichtungen unter anderem dazu diente, Figuren effektvoll voneinander als Gut und Böse abzugrenzen (also als Polarisationsmittel), indem die Angst auf mangelndes Gottvertrauen und Weltverfallenheit hindeutete und den Bösen somit als gottlos kennzeichnete (vgl. Gerok-Reiter 2007: 133). So wird auch die böse Königin in den Grimm'schen Versionen als „gottlos“ bezeichnet (Rölleke 1986: 259, Grimm 2000: 255) und ihr Schicksal als abschreckendes Beispiel eines Charakters dargelegt, der sich im Verlaufe des Märchens aufgrund der ihm innewohnenden Ängste selbst zu Grunde richtet. Ihr gegenübergestellt wird das gute Schneewittchen, deren Ängste, wie sich herausstellen wird, nicht in ihrem Charakter selbst angelegt sind, sondern sich vielmehr situativ äußern.

\subsection{Der Mordanschlag durch den Jäger}

Der Konflikt aller drei Versionen spitzt sich dahingehend zu, dass die Königin den Entschluss fasst, Schneewittchen vom Jäger in den Wald führen und ermorden zu lassen. Dies führt zur ersten Angstsituation, der Schneewittchen innerhalb des Märchens ausgesetzt ist und die Rezipierenden gewissermaßen mit ihm auszustehen haben. Hier wiederum findet sich ein weiterer Unterschied der Disney-Version zu den Grimm-Fassungen. Während die Informationen über das Schneewittchen bei den Grimms zunächst darauf reduziert bleiben, dass es mit sieben Jahren viel schöner wurde als die Königin selbst, erhält das DisneySchneewittchen, wie auch die Disney-Königin, eine detailreichere Beschreibung:

Dabei war es schwer vorstellbar, dass irgendwer Schneewittchen etwas Böses wollen könnte. Die Prinzessin war nicht nur wunderschön, sondern auch sanftmütig und freundlich. Sie kümmerte sich liebevoll um ihre einzigen Freunde, die Vögel, und verrichtete ihre schwere Arbeit jeden Tag mit einem Lächeln auf den Lippen, ohne sich jemals zu beklagen. (Disney 2018: 14)

Die Abgrenzung von der Königin wird hier stärker betrieben als bei den Grimms: Der Grausamkeit und Schreckensherrschaft der niemals lächelnden Königin 
wird die liebevolle Sanftmut des ewig lächelnd-freundlichen Schneewittchens gegenübergestellt. Somit scheinen die Figuren über die für Märchen übliche einfache Charakterzeichnung hinaus in Stereotypen eines „zerstörerischen Dämons“ und eines „unschuldigen Engels“ (vgl. Disney 2018: 23, „wie ein Engel“) transformiert worden zu sein (vgl. Whitley 2012: 24). Gerade die Idealisierung Schneewittchens führt aber zu einem unterschiedlichen Angstempfinden für sowohl die Figur als auch die Rezipierenden:

[...] „führ das Sneewittchen hinaus in den Wald an einen weiten abgelegenen Ort, da stichs todt, und zum Wahrzeichen bring mir seine Lunge und Leber mit, die will ich mit Salz kochen und essen." [...] wie er aber den Hirschfänger gezogen hatte und eben zustechen wollte, da fing es an zu weinen, und bat so sehr, er mögt ihm sein Leben lassen, es wollt nimmermehr zurückkommen, sondern in dem Wald fortlaufen. (Rölleke 1986: 247)

„Bring das Kind hinaus in den Wald, ich wills nicht mehr vor meinen Augen sehen. Du sollst es Töten und mir Lunge und Leber als Beweis mitbringen.“ Als er den Hirschfänger zog und damit Schneewittchens unschuldiges Herz durchbohren wollte, fing es an zu weinen und sagte: „Ach, lieber Jäger, lass mir mein Leben: ich will in den wilden Wald laufen und nie wieder nach Hause kommen.“ (Grimm 2000: 236)

Die Königin aber befahl ihrem Jäger Schneewittchen in den Wald zu bringen und dort zu töten. Das Mädchen folgte dem Jägersmann still, bis es am Wegesrand ein kleines Vöglein bemerkte, das aus dem Nest gefallen war. Schneewittchen kniete sich hin, um es aufzuheben und zu trösten. In dem Moment fiel ein Schatten über sie. Als Schneewittchen sich umsah, stand hinter ihr der Jäger mit erhobenem Dolch - bereit den Auftrag der Königin auszuführen. Schneewittchen schaute dem Jäger in die Augen. (Disney 2018: 15-16)

Die Gesamtsituation stellt sich hier als höchst angsteinflößend dar: Besonders die 1812er Version betont die Abgelegenheit des Waldes und damit die ausdrückliche Bedrohlichkeit der Situation. Auch wird in den Grimm-Versionen das beängstigende Anliegen der Königin zum Ausdruck gebracht, sich Schneewittchens Organe, möglicherweise als Symbol für ihre Schönheit und Anziehungskraft, einverleiben zu wollen (vgl. Bettelheim 1977: 196). Zum Höhepunkt der Angstdarstellung und dem Moment, in dem die Rezipierenden am deutlichsten dazu aufgefordert sind, mit Schneewittchen mit $\mathrm{zu}$ leiden und $\mathrm{zu}$ fürchten, kommt es, als dieses weinend um ihr Leben bitten muss. Hier nun stellt sich die 1850er Variante dramatischer dar, indem der Erzähler zugunsten der Figur in den Hintergrund rückt und Schneewittchen ihre Gefühle durch direkte Rede aussprechen lässt, wodurch ihm die Rezipierenden automatisch näherkommen (vgl. Kaiste 2005: 23).

Die Disney-Version grenzt sich eindeutig vom Grimm-Märchen ab: Zuerst wird Schneewittchens Idealisierung weiter vorangetrieben, indem sie halt macht, um einem Tier zu helfen - in diesem Moment wird ebenfalls Bedrohung 
deutlich, indem der Schatten des Jägers über sie fällt. Dieser signalisiert aufgrund seiner Dunkelheit nicht bloß an sich schon Gefahr, sondern zeigt den Rezipierenden zudem das Größenverhältnis zwischen dem Jäger (groß, mächtig, bedrohlich) und Schneewittchen (klein, hilflos, schutzlos). Dann jedoch, anstatt die menschliche Reaktion zu zeigen, die sich in den Grimm-Versionen findet und den Rezipierenden ein Hineinversetzen in die Figur erlaubt, blickt das Disney-Schneewittchen im Angesicht des Todes dem Jäger bloß in die Augen. Diese eher unglaubwürdige Reaktion impliziert weniger unmittelbare Angst seitens Schneewittchens, womöglich aufgrund eines inneren Vertrauens auf ihre Unschuld und Reinheit, was wiederum weniger angstauslösend auf die Rezipierenden wirkt - er muss nicht um sie fürchten. Die Situation löst sich folgendermaßen auf:

Den Jäger erbarmte es, weil es so schön war und gedachte: die wilden Thiere werden es doch bald gefressen haben, ich bin froh, daß ich es nicht zu tödten brauche, und weil gerade ein junger Frischling gelaufen kam, stach er den nieder, nahm Lunge und Leber heraus und brachte sie als Wahrzeichen der Königin mit, die nahm sie kochte sie mit Salz und aß sie auf, und meinte sie hätte Sneewittchens Lunge und Leber gegessen. (Rölleke 1986: 247)

Und weil es so schön war, hatte der Jäger Mitleid und sagte: „So lauf hin du armes Kind“ „die wilden Tiere werden dich bald gefressen haben“, dachte er, und doch war es ihm, als wäre ein Stein von seinem Herzen gewälzt, weil er es nicht zu töten brauchte. Und als gerade ein junger Frischling daher gesprungen kam, stach er ihn ab, nahm Lunge und Leber heraus, und brachte sie als Wahrzeichen der Königin mit. Der Koch mußte sie in Salz kochen, und das boshafte Weib aß sie auf und meinte sie hätte Schneewittchens Lunge und Leber gegessen. (Grimm 2000: 236)

Und als er sah, wie gut und unschuldig das Mädchen war, brachte er es nicht übers Herz, ihm etwas anzutun. Er ließ seine Waffe fallen und senkte den Kopf. „Vergib mir“, sagte er. „Die Königin hat mir befohlen, dich zu töten, doch ich kann es nicht. Lauf fort und komm niemals zurück!““(Disney 2018: 16)

In beiden Grimm-Versionen erbarmt sich der Jäger aufgrund der Schönheit Schneewittchens, jedoch mit der Einschränkung, dass seine Aufgabe im gefährlichen Wald von den wilden Tieren erfüllt werden wird - dies deutet bereits die folgende Angstsituation an, die Schneewittchen zu meistern hat. In der Version von 1850 gibt es zusätzlich einen Verweis auf die Angst des Jägers vor dem verwerflichen Mord an dem unschuldigen Mädchen: Als er das Kind gehen lässt, befreit er sich zugleich von einer steingleichen Schwere, die zuvor auf seinem Herzen lastete. Kövecses (1990: 70-79) beschreibt Angst als eine Emotion, die sich durch eine Reihe von physiologischen Effekten und Verhaltensauffälligkeiten charakterisieren lässt und zu deren Beschreibung auf zahlreiche metaphori- 
sche Wendungen zurückgegriffen werden kann. Demzufolge wird hier die Angst des Jägers durch eine „FEAR (DANGER) IS A BURDEN“ Metapher ausgedrückt, welche Angst als eine unangenehme Last dargestellt, deren Wegfall eine erhebliche Erleichterung mit sich bringt (vgl. ebd. 77f.). Fiehler (2011: 26) hingegen spricht in diesem Zusammenhang von „Konzeptualisierungen, die die Dimension Höhe/Tiefe benutzen, wobei positiv bewertete Entitäten hoch und negativ bewertete tief sind“ - das positive Gefühl, Schneewittchen zu verschonen, äußert sich demnach als Gewichtsverlust, welcher durch den vom Herzen fallenden Stein ausgedrückt wird.

In der Disney-Version erbarmt sich der Jäger hingegen, weil er erkennt, wie „gut und unschuldig“ Schneewittchen ist, ja er wird regelrecht demütig und bittet sie um Verzeihung. Weder ist vorher von dem Verzehr von Organen die Rede, noch von der Frischlingsleber und -lunge als Ersatzmahl für die Königin, noch werden wilde und gefräßige Waldtiere erwähnt - die Angstdarstellung ist im Vergleich zu den Grimm-Fassungen deutlich reduziert.

\subsection{Flucht in den Wald}

Sneewittchen aber war in dem großen Wald mutterseelig allein, so daß ihm recht Angst ward und fing an zu laufen und zu laufen über die spitzen Steine, und durch die Dornen den ganzen Tag [...]. (Rölleke 1986: 247)

Nun war das arme Kind in dem großen Wald mutterseelenallein und ihm wurde so Angst, dass es alle Blätter an den Bäumen ansah und nicht wusste, wie es sich helfen sollte. Da fing es an zu laufen und lief über die spitzen Steine und durch die Dornen [...]. Es lief, solange die Füße konnten, bis es bald Abend werden wollte. (Grimm 2000: 237)

Die Prinzessin lief tief in dem Wald hinein. Als die Nacht anbrach, schienen die Bäume nach ihr greifen zu wollen und Schneewittchen fürchtete sich. Sie stolperte über eine Wurzel zu Boden und begann bitterlich zu weinen. Wohin nur sollte sie gehen? (Disney 2018: 17)

Die Flucht in den Wald ist aus vielerlei Gründen sowohl für die Märchenfigur, als auch in der Vorstellungswelt der Rezipierenden höchst bedrohlich:

Am deutlichsten wohl spricht das Märchen von seelischer Not, wenn sein Held verlassen und ausgestoßen in der Welt steht, wenn er sich seiner Schwäche inne wird in der Begegnung mit einer ihn bedrohenden Welt. Die Gefahr schaut in solchen Situationen aus der Welt auf ihn und erregt in [...] [ihm] das Gefühl der Furcht vor einer Übermacht. (Gerstl 1964: 74)

Das Verlassen-Werden und Ausgestoßen-Sein in fremder Umgebung stellt wiederum eine elementare Angst des Menschen dar, denn es beinhaltet nicht bloß 
die Hilflosigkeit angesichts der lauernden Gefahren, sondern, wie Gerok-Reiter feststellt, ebenfalls den Verlust des sozialen Integrationsrahmens: Durch das Einbüßen des vertrauten Sozialisationsgefüges ist man - zumindest in der mittelalterlichen Welt und auch der Welt des Märchens - den Unwägbarkeiten der Natur schutzlos ausgeliefert (vgl. Gerok-Reiter 2007: 141). Somit sind sowohl die Angst des Schneewittchens als auch tatsächliche Befürchtungen für das Schneewittchen seitens der Rezipierenden hier höchst nachvollziehbar.

Betrachtet man die beiden Grimm Versionen im Vergleich, so sind beide nach dem Muster „Verlassen-Werden - Realisieren des Alleinseins - Angst Flucht“" aufgebaut, jedoch unterscheidet sich der Angstzustand Schneewittchens dahingehend, dass er „verschiedenen Stufen literarischer Bewußtheit entspricht“ (Dettmering 1984: 159). Während in der älteren Fassung Schneewittchen lediglich Angst bekommt und anfängt zu laufen, ist die Beschreibung in der späteren Fassung komplexer und reflektierter, da Schneewittchen in ihrer Angst beginnt ihre Umwelt als sonderbar, entfremdet und fragmentiert wahrzunehmen, indem sie alle Blätter an den Bäumen einzeln betrachtet (vgl. ebd.). Die Angst kann außerdem mit einem Verlust der Kontrolle über das eigene Verhalten zusammenfallen (vgl. Dobrovol'skij 1995: 334, 337), welches sich bei Schneewittchen in einer Flucht ungeachtet der sie verletzenden Natur und in der 1850er Version bis hin zur völligen körperlichen Erschöpfung (bis sie die Füße nicht mehr tragen) äußert.

Auch in der Disney-Version bekommt es Schneewittchen erstmals mit der Angst zu tun und sie verliert sich nicht bloß im Wald, sondern auch in ihrer eigenen subjektiven Einbildungskraft (vgl. Whitley 2012: 21), indem sie die Bäume nach ihr greifen sieht und die Natur somit personifiziert und in ein gefährliches Wesen transformiert wahrnimmt. Ihre Flucht findet hier außerdem, im Gegensatz zu den Grimms, bei Nacht statt, womit hier eine gruseligere Atmosphäre generiert wird.

\subsection{Erster und zweiter Mordanschlag durch die Königin}

Nach ihrer angsterfüllten Flucht durch den Wald findet Schneewittchen letztendlich in allen Versionen die schutzspendende Waldhütte der Zwerge. Auch hier sei jedoch ein Unterschied in der Darstellung Schneewittchens angemerkt: Während sie in den Grimm-Fassungen nach der anstrengenden Reise durch den Wald zunächst darauf bedacht ist, ihre körperlichen Bedürfnisse zu befriedigen und deshalb aus jedem Becherchen trinkt, von jedem Tellerchen isst und schließlich vor dem Schlafengehen jedes Bettchen einmal ausprobiert, verhält sich dies in der Disney-Version ganz anders. Schneewittchen klopft hier brav 
und bittet um Einlass, findet beim Eintreten ein heilloses Chaos vor und reinigt und putzt das gesamte Haus, bevor sie sich schließlich schlafen legt.

Dies zu erwähnen ist von Bedeutung, da wiederum die Idealisierung des Disney-Schneewittchens hin zu einer Vorbild-Rolle hervorsticht - trotz ihrer kindlichen Erscheinung besitzt sie bereits die Charaktereigenschaften und Fähigkeiten einer idealen erwachsenen Hausfrau (vgl. Whitley 2012: 32) und muss deshalb auch in keiner Weise belehrt und erzogen werden. Dementsprechend fehlen in der Disney-Version zwei der drei ursprünglichen Mordversuche der Königin, die bei den Grimms eine zentrale pädagogische Funktion einnehmen. Und somit fehlt auch die sich immer steigernde Angst der Königin aufgrund abermalig scheiternder Anschläge und die immer größere Angst der Rezipierenden um das Schicksal Schneewittchens, da die Mordversuche der Königin sich durch die zunehmende Heimtücke auszeichnen.

In den Grimm-Versionen erlauben die Zwerge Schneewittchen zu bleiben, wenn diese für sie die alltäglichen Hausarbeiten verrichtet. Sich diese Welt der Arbeit zu eigen zu machen, stellt hier einen zentralen Bestandteil des Heranwachsens und der Entwicklung Schneewittchens dar (vgl. Bettelheim 1977: 198). Zudem warnen die Zwerge Schneewittchen vor ihrer Mutter/Stiefmutter:

Abends kommen wir nach Haus, da muß das Essen fertig seyn, am Tage aber sind wir im Bergwerk und graben Gold, da bist du allein; hüt dich nur vor der Königin und laß niemand herein. (Rölleke 1986: 251)

Den Tag über war das Mädchen allein; darum warnten es die guten Zwerge und sprachen: „Hüte dich vor deiner Stiefmutter, die wird bald wissen, dass du hier bist; lass ja niemand herein.“ (Grimm 2000: 243)

Das Märchen folgt nun einer leicht erkennbaren Strukturformel, nämlich dem Verbot der Zwerge, jemanden einzulassen/dem Gebot zur Vorsicht - der Übertretung durch Schneewittchen - und der darauffolgenden Rettung bzw. Strafe: Erzählungen dieser Art lehren, dass die Missachtung der Normen der Bezugspersonen und der Gesellschaft aufgrund von Trieben wie Neugier, Ungehorsam und kindlicher Lust schlimme Folgen haben können und haben somit u. a. norm- und regelstiftende Funktion (vgl. Kaiste 2005: 26, 53-55). Es soll also durch die Erzeugung von Angst vor ähnlichen Strafen, wie sie der Märchenheld erleidet, zum Gehorsam erzogen werden (vgl. ebd. 15). In der Disney-Version würden ein solches Ungehorsam, die Möglichkeit der Verführung durch das Böse oder kindliche Charakterfehler, die zur Missachtung von Geboten führen, sich in den idealisierten Charakter Schneewittchens nicht einfügen, weshalb es dort auch nicht zu einer solchen Belehrung kommt. 
Die Königin in beiden Grimm-Versionen glaubt nun Schneewittchens Leber und Lunge verspeist zu haben und tritt in der Erwartung vor den Spiegel, wieder die Allerschönste im Lande zu sein. Da sich ihre Erwartung nicht bewahrheitet und sie den Betrug ihres Jägers feststellen muss, wird sie jedoch umso mehr „erschreckt“ (Rölleke 1986: 251, Grimm 2000: 244). Unfähig dazu, Ruhe zu finden, solange sie der Spiegel nicht zur Schönsten erklärt, verkleidet sich die Königin und konfrontiert Schneewittchen selbst:

Sneewittchen guckte aus dem Fenster: „was habt ihr denn?“- „Schnürriemen, liebes Kind [...] willst du den haben?“ - Ei ja, sprach Sneewittchen, und dachte die gute alte Frau kann ich wohl hereinlassen, die meints redlich; riegelte also die Thüre auf [...] Schneewittchen stellte sich vor sie, da nahm sie den Schnürriemen und schnürte und schnürte es so fest, daß ihm der Athem verging, und es für todt hinfiel. Darnach war sie zufrieden und ging fort. (Rölleke 1986: 251-252)

Schneewittchen guckte zum Fenster hinaus und rief: „Guten Tag, liebe Frau, was habt ihr zu verkaufen?“ [...] „Schnürriemen von allen Farben“ [...] Die ehrliche Frau kann ich hineinlassen, dachte Schneewittchen, riegelte die Tür auf und kaufte sich den hübschen Schnürriemen.[...] Schneewittchen hatte kein Arg, stellte sich vor sie hin und ließ sich mit dem neuen Schnürriemen schnüren. Aber die Alte schnürte geschwind und schnürte so fest, dass dem Schneewittchen der Atem wegblieb, und es wie tot hinfiel. „Nun bist du die Schönste gewesen“, sagte die Alte und eilte hinaus. (Grimm 2000: 245)

Was sich als besonders beängstigend darstellt, ist die Fähigkeit der Königin, sich - und damit das Böse selbst - bis zur Unkenntlichkeit zu verschleiern, so dass Schneewittchen sie für „redlich“/,ehrlich“ hält, obgleich sie das genaue Gegenteil darstellt. Das Böse übt hier durchaus eine Art von Faszination auf Schneewittchen aus (vgl. Bettelheim 1977: 14), weshalb sie das Verbot übertritt und gewissermaßen das Böse zur Türe hineinlässt. Schneewittchen wird nicht als perfekter Charakter präsentiert, sie ist nicht bloß aufgrund ihrer Schönheit und Unschuld in Gefahr, sondern auch aufgrund ihrer Gutgläubigkeit und Verführbarkeit - dies hat beinahe ihren Tod zur Folge, was auf die Rezipierenden eine äußerst abschreckende Wirkung haben sollte. Doch die Zwerge eilen ihr noch rechtzeitig zur Hilfe und sprechen daraufhin ein zweites Verbot aus. ${ }^{4}$

Als die Königin nun abermals vor den Spiegel tritt und dieser ihr wiederum die Lebendigkeit und Schönheit Schneewittchens verkündet, steigert sich ihre Angst erneut:

4 Auch die Zwerge erschrecken sich und haben Angst um Schneewittchen, da sie sie leblos am Boden liegend finden, dies gehört jedoch eher zum Nebengeschehen und soll hier nicht im Detail aufgeführt werden. 
Sie erschrack, daß das Blut ihr all zum Herzen lief, da sie sah, daß Sneewittchen wieder lebendig geworden war. (Rölleke 1986: 253)

Als sie das hörte, lief ihr alles Blut zum Herzen, so sehr erschrak sie, denn sie wusste, dass Schneewittchen wieder lebendig geworden war. (Grimm 2000: 247)

Wiederum zeigt sich hier eine körperliche Reaktion in Verbindung mit der Herzmetaphorik, die sich durch das Märchen zu ziehen scheint - auf eine etwas ungewöhnliche Art wird vermutlich beschrieben, wie das Blut der Königin in Folge des Schrecks in Wallung gerät, also ein erhöhter Puls und Blutdruck ausgelöst wird. Dies reiht sich wiederum in Kövecses Feststellungen ein, der die Beschleunigung der Herzfrequenz („INCREASE IN HEART RATE“) als einen durch Angst ausgelösten physiologischen Effekt unter seinen Metonymien der Angst aufführt (vgl. Kövecses 1990: 70). Zu der elementaren Angst vor dem Altern scheint zudem nun eine weitere Angst zu stoßen: die Angst vor der scheinbaren Unüberwindbarkeit des immer wieder auferstehenden Schneewittchens.

Für die zweite Konfrontation mit Schneewittchen muss die Königin also ein größeres Maß an Macht aufwenden, als zuvor. In der Version von 1850 stellt sie einen giftigen Kamm mit Hilfe von „Hexenkünsten“ (Grimm 2000: 247) her. Was also in der Disney-Variante von vorne herein vorausgesetzt wurde - die Hexenkraft der Königin - wird hier, zumindest in der späteren Grimm-Version, erst im Verlaufe der Handlung aufgedeckt und bringt so eine Spannungssteigerung mit sich, da die Rezipierenden nicht wissen, welche verborgenen Fähigkeiten die Königin außerdem noch besitzen mag.

Bei der zweiten Konfrontation öffnet Schneewittchen nun der verkleideten Königin nicht sofort die Tür, sondern erklärt in beiden Versionen, dass sie niemanden hineinlassen darf. Die Königin hält jedoch den vergifteten Kamm in die Höhe:

[...] da zog sie den Kamm hervor, und als Sneewittchen den blinken sah und es auch jemand ganz fremdes war, so machte es doch auf [...] kaum aber stack der Kamm dem Sneewittchen in den Haaren, da fiel es nieder und war todt. „Nun wirst du liegen bleiben," sagte die Königin, und ihr Herz war ihr leicht geworden ${ }^{5}$, und sie ging heim. (Rölleke 1986: 253)

Da gefiel er dem Kind so gut, dass es sich betören ließ und die Tür öffnete. [...] Das arme Schneewittchen dachte an nichts Böses und ließ die Alte gewähren: aber kaum hatte sie den Kamm in die Haare gesteckt, als das Gift darin wirkte und das Mädchen ohne Besin-

5 Hier findet sich die gleiche Reaktion, wie sie der Jäger erlebt, als er das Schneewittchen gehen lässt: Das Freiwerden von Angst stellt sich als Freiwerden von einer Last dar, die das Herz beschwert hatte. 
nung niederfiel. „Du Ausbund von Schönheit“, sagte das boshafte Weib, „jetzt ists um dich geschehen“, und ging fort. (Grimm 2000: 248)

Schneewittchen kann sich der magischen Anziehungskraft des Kammes nicht erwehren, er „blinkt“ und „betört“ sie und diese Verführungskraft des Bösen führt sie wiederum dazu, das Gebot der Zwerge zu brechen und dies mit harter Strafe $\mathrm{zu}$ bezahlen. Auf diese Weise wird immer deutlicher, dass nicht bloß davor gewarnt werden soll, elterliche Normen zu missachten, sondern auch davor, sich aufgrund von Gutgläubigkeit oder materiellen Wünschen und Sehnsüchten der Verführung des Bösen selbst hinzugeben. Dennoch macht vielleicht gerade diese Unfähigkeit, der Versuchung zu widerstehen, das Schneewittchen umso menschlicher und sympathischer (vgl. Bettelheim 1977: 198) und erlaubt es den Rezipierenden so, aufgrund der nachhaltigen Identifikation mit ihr, eine größere Lehre aus der Märchenhandlung zu ziehen. Die Zwerge erreichen Schneewittchen jedenfalls abermals zur rechten Zeit und sprechen schließlich ein drittes und letztes Verbot aus.

\subsection{Dritter Mordanschlag durch die Königin}

Wieder tritt die Königin vor den Spiegel und wieder bewahrheiten sich ihre Ängste:

Wie das die Königin wieder hörte, zitterte und bebte sie vor Zorn: „,so soll das Sneewittchen noch sterben, und wenn es mein Leben kostet!“ Dann ging sie in ihre heimlichste Stube, und niemand durfte vor sie kommen, und da machte sie einen giftigen, giftigen Apfel, äußerlich war er schön und rothbäckig, und jeder der ihn sah, bekam Lust dazu. (Rölleke 1986: 255)

Als sie den Spiegel so reden hörte, zitterte und bebte sie vor Zorn. „Schneewittchen soll sterben“, rief sie, „und wenn es mein eigenes Leben kostet.“ Darauf ging sie in eine ganz verborgene, einsame Kammer, wo niemand hinkam, und machte da einen giftigen Apfel. Äußerlich sah er schön aus, weiß mit roten Backen, dass jeder, der ihn erblickte, Lust danach bekam; aber wer ein Stückchen davon aß, der musste sterben. (Grimm 2000: 249)

Auch hier zeigt sich eine körperliche Reaktion der Königin, die man in diesem Zusammenhang wohl wieder als Ausdruck von Angst verbunden mit einer anderen starken Emotion, diesmal mit heftigem Zorn, interpretieren kann. Dobrovol'skij (1995: 328f., 320) ordnet seine Angst-Idiome vier imaginär-konzeptuellen Bereichen zu: Angst als Kälte, unangenehme Empfindung im analen Bereich, körperliche Schwäche und als feindliches Wesen: Das „zittern und beben“ der Königin, wenn es auch dem Zorn zugeordnet wird, kann hier mit der 
konzeptuellen Metapher „ANGST ALS KÄLTE“ verbunden werden, wenn man davon ausgeht, dass die elementare Angst der Königin vor dem Altern - und nun auch vor Schneewittchen selbst - ausschlaggebend für ihre anderen starken Emotionen ist. Auch Kövecses führt „zittern“ unter seinen AngstMetonymien auf, und zwar im Bereich „PHYSICAL AGITATION“ (Kövecses 1990: 70).

Dass die Königin für ihren letzten Mordanschlag nun all ihre Macht aufwendet zeigt sich daran, dass sie in beiden Grimm-Fassungen ihre heimlichste Kammer aufsucht, zu der nur sie selbst Zugang hat. Es wird impliziert, dass der giftige Apfel aus einem solch geheimen und damit bedrohlichen Vorgang entsteht, dass keine Menschenseele davon wissen darf. In der Version von 1850 wird zudem das scheinbar unvermeidliche Ende angedeutet: Wenn Schneewittchen ein Stück von dem Apfel probiert, muss sie sterben. Durch die drei aufeinanderfolgenden Mordanschläge in den Grimm-Fassungen wird somit dreierlei erreicht: 1. Die sich steigernde Angst der Königin wird demonstriert, indem diese immer aufs Neue den Spiegel konfrontieren muss, 2. Ihre gesteigerte Angst führt zu der Verstärkung anderer Emotionen (beispielsweise Zorn) und in der Folge $\mathrm{zu}$ verstärktem Machtaufwand, um Schneewittchen endlich zu vernichten, 3. Dies führt zu einer Spannungssteigerung für die Rezipierenden und gleichzeitig einem verstärkten Mitfühlen und -fürchten mit Schneewittchen, da er bei jeder neuen Konfrontation die Entwicklung der Königin zu einer noch bösartigeren Kontrahentin beobachten muss.

Der dritte Anschlag der Grimm'schen Königin ist nun der erste Anschlag der Disney-Fassung:

\footnotetext{
„Das ist unmöglich!“, schrie die Königin. „Schneewittchen ist tot!“ [...] Wutentbrannt schloss die Königin sich daraufhin in ihren Gemächern ein und braute einen Zaubertrank aus Schlangengift, fauligem Wasser und schierer Böswilligkeit. Dieses Gebräu schluckte die Königin hinunter und verwandelte sich auf der Stelle in eine hässliche alte Hexe. Dann griff sie nach einem schönen, roten Apfel und tauchte ihn in einen Topf voll Gift. „Ein Biss von diesem Apfel und Schneewittchens Augen schließen sich für immer." Sie kicherte böse. „Dann bin ich endlich wieder die Schönste im ganzen Land!“ (Disney 2018: 28)
}

Der wichtigste Unterschied $\mathrm{zu}$ den Grimm-Fassungen, neben der bereits erwähnten mangelnden Angst- und Spannungssteigerung, ist die Verwandlung der Königin in eine Hexe: Bereits die Umwandlung der ursprünglichen Mutter im Grimm-Märchen von 1812 zur bösen Stiefmutter in der 1850er Version zeigt einen Prozess an, der darauf ausgerichtet ist, die Königin unnatürlicher und unmenschlicher zu machen (vgl. Whitley 2012: 23). Dies kulminiert in der Disney-Variante darin, dass die Königin durch ihre Transformation tatsächlich nicht mehr menschlich zu sein scheint und fortan bis zum Ende des Märchens 
hauptsächlich den Titel Hexe trägt. Die Vorstellung der Hexe hat auf die Rezipierenden durchaus eine angsteinflößende Wirkung:

Angst und Schrecken gegenüber Hexen und ihrer magisch-archaischen Bösartigkeit und Machtfülle sind im Märchen immer wieder zentrales Thema [...] [besonders,] weil sie Bilder und Namen für eigentlich namenlose Ängste und kaum artikulierbare, lebensgeschichtlich frühe Wünsche von Leser und Zuhörer bereitstellen. (Trescher 1985: 55).

Ein weiterer auffälliger Aspekt ist die später noch häufiger auftretende Verwendung eines Euphemismus, also die verhüllende Beschreibung des Todes, der als tabuisierter Sachverhalt gilt: „Schneewittchens Augen schließen sich für immer“ (Disney 2018: 28) dient als Umschreibung ihres sich andeutenden Todes (vgl. Nübling 2017: 156).

Als in den Grimm-Versionen nun die verkleidete Königin erneut vor Schneewittchen tritt, weigert sich diese zunächst vehement, die Frau einzulassen, indem sie auf das Verbot der Zwerge verweist. Doch die Königin ist auf Angst und Skepsis vorbereitet und weiß einen noch bösartigeren Weg der Verführung, als zuvor:

\begin{abstract}
„Ihr mögt Euch wohl fürchten, da ich will den Apfel entzwei schneiden und die Hälfte essen, da den schönen rothen Backen sollt ihr haben;“ der Apfel aber war so künstlich gemacht, daß nur die rote Hälfte vergiftet war. Da sah Sneewittchen, daß die Bäuerin selber davon aß, und sein Gelüst darnach ward immer größer [...] kaum aber hatte es einen Bissen im Mund, so viel es todt zur Erde. (Rölleke 1986: 255)

„Fürchtest du dich vor Gift?“ sprach die Alte, „siehst du, da schneide ich den Apfel in zwei Teile; die rote Hälfte iss du, die weiße will ich essen." Der Apfel war aber so künstlich gemacht, dass die rote Hälfte allein vergiftet war. Schneewittchen gelüstete es nach dem schönen Apfel [...]. Kaum aber hatte es einen Bissen davon im Mund, so fiel es tot zur Erde nieder. (Grimm 2000: 250)
\end{abstract}

Die Königin spricht die mögliche Angst Schneewittchens direkt an und macht das Angebot, den Apfel zu teilen - so gelingt es ihr, das Mädchen erneut auf eine kunst- und trickreiche Art zu verführen: Es wird aufs Neue vor der Macht, Hinterhältigkeit und Tücke des Bösen, aber auch vor der Hingabe an bedrohliche Sünden gewarnt. Besonders beängstigend für die Rezipierenden ist zudem, dass nicht wie bisher der bloß scheinbare Tod Schneewittchens sprachlich in Form von irrealen Vergleichssätzen angedeutet wird (z. B. „und es für todt hinfiel“ (Rölleke 1986: 252), „und es wie tot hinfiel“ (Grimm 2000: 245)) sondern sie nun tatsächlich tot zur Erde niederfällt, ihr Tod somit besiegelt zu sein scheint.

In der Disney-Variante trifft Schneewittchen zum ersten Mal auf die Königin: 
„Guten Morgen, schönes Kind“, rief die Frau. „Wie ich sehe, arbeitest du fleißig. Möchtest du dich nicht einen Moment ausruhen und einen meiner Äpfel kosten? Mein Korb ist sowieso zu schwer für mich." Schneewittchens gefiederte Freunde aber erkannten die Königin. Sie pickten nach ihr und schlugen die Flügel in ihr Gesicht, um sie zu verjagen. Schneewittchen hatte jedoch Mitleid mit der alten Frau und ließ sie herein. Die alte Frau reichte ihr einen schönen, roten Apfel und Schneewittchen biss herzhaft hinein. In dem Moment aber, indem ihre Lippen den vergifteten Apfel berührten, wich alles Leben aus ihr. (Disney 2018: 30-31)

Weder wurde es Schneewittchen zuvor von den Zwergen verboten, jemanden einzulassen, weshalb sie auch kein Verbot übertritt, noch wird sie durch das Böse dazu verleitet. Vielmehr lässt Schneewittchen die Königin aus Mitleid in die Stube ein. Die finale Konfrontation wird in der Disney-Variante nicht langsam aufgebaut, sondern findet unmittelbar statt, was den Rezipierenden wenig Raum gibt, sich in Schneewittchen hineinzuversetzen und mit ihr mitzufühlen. So wird auch die Möglichkeit einer immer bedrohlicheren Entwicklung der Königin umgangen. Zudem wird auch hier das Euphemismus wich alles Leben aus ihr verwendet, um den Tod des Mädchens nicht direkt aussprechen zu müssen und das Angstpotential zu mindern.

\subsection{Auflösung}

Für die Rezipierenden kommt es nun in den Grimm-Versionen zum Höhepunkt der Angst um Schneewittchen und zur verzweifeltsten Situation des Märchens, was vor allen Dingen durch die Reaktion der Zwerge vermittelt wird:

„Spieglein, Spieglein an der Wand: wer ist die schönste Frau in dem ganzen Land?“ Da antwortete er: „Ihr, Frau Königin, seyd die Schönste Frau im Land!“ „Nun hab ich Ruhe“ sprach sie, „da ich wieder die Schönste im Lande bin, und Sneewittchen wird diesmal wohl todt bleiben." [...] da lag das liebe Sneewittchen auf dem Boden und war todt. Sie schnürten es auf und sahen, ob sie nichts giftiges in seinen Haaren fänden, es half aber alles nichts, sie konnten es nicht wieder lebendig machen. (Rölleke 1986: 257)

Da betrachtete es die Königin mit grausigen Blicken und lachte überlaut, und sprach „weiß wie Schnee, rot wie Blut, schwarz wie Ebenholz! Diesmal können dich die Zwerge nicht wieder erwecken." [...] fanden Schneewittchen auf der Erde liegen, und es ging kein Atem mehr aus seinem Mund, und es war tot. Sie hoben es auf, suchten ob sie etwas Giftiges fänden, schnürten es auf, kämmten ihm die Haare, wuschen es mit Wasser und Wein, aber es half alles nichts; das liebe Kind war tot und blieb tot. (Grimm 2000: 251)

Der Spiegel, dessen wahrheitssprechende Funktion im Märchen bereits etabliert wurde, bestätigt auf diese Weise das Schicksal Schneewittchens und raubt den Rezipierenden so vorübergehend die Hoffnung auf ein erneutes Wiederaufleben 
des Kindes. Untermalt wird diese beängstigende Situation, vor allem in der späteren Fassung, durch die grausige Reaktion der auf dem Höhepunkt ihrer Boshaftigkeit sich befindenden Königin. Schließlich kehren die Zwerge zurück und suchen vergeblich und immer verzweifelter nach der Ursache der vermeintlichen Ohnmacht Schneewittchens, doch sie können Schneewittchen nicht noch einmal retten - sie „war tot und blieb tot“ (Grimm 2000: 251). Die DisneyVersion kommt an diesem Punkt bereits zur Auflösung, also zum Ende des Handlungsstrangs der Königin - wie sich herausstellen wird aus mehreren Gründen:

Darauf stieß die alte Hexe ein teuflisches Lachen aus, das weit durch den Wald zu hören war [...]. Ein Gewitter braute sich über ihnen zusammen und bald regnete es in Strömen. Die Hexe aber sah die Zwerge kommen und flüchtete so schnell sie konnte durch das Unwetter vor ihnen. Blitz und Donner tobten, als die Zwerge mit den Waldtieren die Verfolgung aufnahmen. Die alte Hexe rannte geschwind und kletterte schließlich eine Felswand hinauf. „Ich zermalme euch“, schrie sie den Zwergen zu und versuchte einen großen Felsbrocken auf sie hinunterzustoßen. In dem Moment aber schlug der Blitz ein - und traf die böse Königin. Darauf fiel sie von der Klippe in einen dunklen Abgrund und ward nie mehr gesehen. Doch zurück in ihrem Häuschen konnten die Zwerge nichts mehr für Schneewittchen tun. Ihre schöne Prinzessin war von ihnen gegangen ${ }^{6}$. (Disney 2018: 31-34)

Die Königin, oder vielmehr Hexe, kehrt hier nicht zu ihrem Spiegel zurück, sondern begibt sich auf die Flucht vor den Zwergen und Waldtieren - es entsteht eine bedrohliche Situation, indem die Naturgewalten ins Spiel gebracht werden. Es scheint, als würde sich die böse Tat der Königin und das Unglück Schneewittchens in den Wetterverhältnissen - in Blitz, Donner, Sturm und Regen wiederspiegeln: Solche katastrophenähnlichen Naturzustände gehören ebenfalls seit jeher zu den elementaren Ängsten der Menschen, da sie diesen zumeist schutzlos ausgeliefert sind (vgl. Dinzelbacher 1993: 327). Die Flucht der Königin vor ihren Verfolgern scheint Angst ihrerseits zu implizieren, möglicherweise Strafangst wegen ihres vorangegangenen grausamen Verbrechens (vgl. Dettmering 1984: 161) - doch ihre letzte Handlung, der Versuch die Zwerge mit einem Felsbrocken zu zerschmettern, drückt vielleicht weniger Angst aus, als dass sie einem Machtbeweis darstellen soll. In diesem Moment, unmittelbar bevor sie eine weitere böse Tat vollbringen kann, trifft sie unvermittelt ein Blitz - die Natur scheint sie für ihre Boshaftigkeit zu strafen.

6 Hier findet sich ein weiterer Euphemismus auf Seiten Disneys, ganz anders als bei den Grimm-Versionen, in welchen die finale Bezeichnung „sie war tot und blieb tot“ gerade Bestandteil der Dramatik war. 
Die Königin wurde jedoch in der Disney-Variante in eine Hexe verwandelt und im Kopf der Rezipierenden auch als eine solche verankert, weshalb sie diesem letztendlich weitgehend unmenschlich erscheint und er die Strafe somit nicht als furchtbar empfinden muss. Außerdem erübrigt sich so die Hinrichtung der Stiefmutter von Menschenhand: Zum einen erlaubt diese Auflösung also die Bestrafung des Bösen - wenn der Tod der Königin auch unausgesprochen bleibt - ohne dass bei dieser Strafe die Billigung Schneewittchens im Stillen angenommen werden müsste, da sich dies mit ihrer idealisierten Darstellung durch die Disney-Version nicht verträgt. Zum anderen muss es so nicht zu der Erwähnung einer so grausamen Strafe kommen, wie sie in den GrimmFassungen stattfindet:

[...] ward die Hochzeit bestellt, und Sneewittchens gottlose Mutter, auch eingeladen [...] „Frau Königin, Ihr seyd die Schönste hier, aber die junge Königin ist noch tausendmal schöner als Ihr!" Als sie das hörte, erschrack sie, und es war ihr so Angst, so Angst, daß sie es nicht sagen konnte. Doch trieb sie der Neid, daß sie auf der Hochzeit die junge Königin sehen wollte, und wie sie ankam, sah sie daß es Sneewittchen war; da waren eiserne Pantoffeln im Feuer glühend gemacht, die mußte sie anziehen und darin tanzen, und ihre Füße wurden jämmerlich verbrannt, und sie durfte nicht aufhören, bis sie sich zu todt getanzt hatte. (Rölleke 1986: 259)

$\mathrm{Zu}$ dem Fest wurde aber auch Schneewittchens gottlose Stiefmutter eingeladen. [...] „Frau Königin, ihr seid die schönste hier, aber die junge Königin ist tausendmal schöner als ihr.“ Da stieß das böse Weib einen Fluch aus, und es wurde ihr so Angst, so Angst, dass sie nicht wusste, was tun. Sie wollte zuerst gar nicht auf die Hochzeit kommen, doch ließ es ihr keine Ruhe, sie mußte fort und die junge Königin sehen. Und wie sie hineintrat, erkannte sie Schneewittchen, und vor Angst und Schrecken stand sie da und konnte sich nicht regen. Aber es waren schon eiserne Pantoffeln über Kohlenfeuer gestellt und wurden mit Zangen hineingetragen und vor sie hingestellt. Da musste sie in die rot glühenden Schuhe treten und so lange tanzen, bis sie tot zur Erde fiel. (Grimm: 255)

Am Ende der Märchen-Versionen der Gebrüder Grimm, in der letzten Auseinandersetzung der beiden Kontrahentinnen, kommt es auch zum Höhepunkt der Angst der Königin. Bis hierhin fand eine stetige Steigerung ihrer Angst statt, doch schien sie letztendlich die Oberhand gewonnen und Schneewittchen vernichtet $\mathrm{zu}$ haben. Gerade der trügerische Glaube an den Tod der Gegnerin lässt ihr Entsetzen umso größer werden, als sich die Königin abermals getäuscht sieht. Die Erfahrungen der vorangegangenen Mordanschläge müssen in ihr die böse Ahnung erwecken, dass es sich bei der jungen Königin um Schneewittchen selbst handelt. In beiden Versionen wird das Ausmaß ihrer Verängstigung zuerst durch die Wiederholung und „es wurde ihr so Angst, so Angst“ betont; in der älteren Version ist die Königin dann unfähig dazu, zu sprechen („INABILITY TO SPEAK“) und in der späteren Version ist sie außerstande zu denken („INABI- 
LITY TO THINK“) - beides wiederum metonymische Angstbereiche nach Kövecses (vgl. Kövecses 1990: 71).

Dennoch kann sie in dieser Angst, wie sich herausgestellt hat, niemals $\mathrm{Ru}$ he finden und obgleich es wahrscheinlich ist, dass sie dort Schneewittchen vorfindet und bestraft wird, treibt ihre Ruhelosigkeit sie schließlich zur Hochzeit. Die 1812er Version verzichtet auf weitere Angstdarstellung und widmet sich umgehend der Strafe, aber die spätere Fassung schildert auch hier die Angstreaktion der Königin beim Anblick Schneewittchens: „Und wie sie hineintrat, erkannte sie Schneewittchen, und vor Angst und Schrecken stand sie da und konnte sich nicht regen“ - die Königin ist also aufgrund ihrer Angst unfähig dazu, sich zu bewegen („INABILITY TO MOVE,“ vgl. Kövecses 1990: 71). Dies rührt wohl daher, dass sie sich wiederum in ihrer Schönheit übertroffen sieht, und zwar abermals durch ihre Nemesis, das scheinbar unsterbliche, unüberwindbare Schneewittchen. Zudem befürchtet sie womöglich, dass sie nun eine ihren Schandtaten gemäße Strafe zu erwarten hat.

Die brutale Strafe für die Königin ist ein Beispiel für die Grausamkeitsdarstellung in Märchen, die von seinen Gegnern so häufig kritisiert wurde. Diese dient aber dem Bedürfnis, unmissverständliche Verhältnisse aufzuzeigen und klare Schlusspunkte zu setzen: Es soll am Ende des Märchens keine Spur von Zweifel zurückbleiben, dass Gerechtigkeit und Reinheit triumphieren (vgl. Maier 1987: 78-79). Zudem wurde von den Märchenverfechtern betont, dass sich das Märchen bei der Beschreibung der Strafen niemals im Detail verliert, keine Wunden beschreibt, kein Blut fließen lässt und die Abrechnung mit dem Bösewicht letztendlich hauptsächlich abschreckend wirkt, da sich zeigt, dass sich dessen Verbrechen nicht auszahlen (vgl. ebd. 79, Bettelheim 1977: 14). Dennoch ist das Tanzen in glühenden Schuhen eine für die Rezipierenden unzweifelhaft angst-einflößende Vorstellung, weshalb in der späteren Version möglicherweise auf den Zusatz „und ihre Füße wurden jämmerlich verbrannt“ (Rölleke 1986: 269) bewusst verzichtet wurde.

Die Grimm'schen Varianten von Schneewittchen zeichnen sich durch zweierlei Lehren aus, die es aus dem Märchen zu ziehen gilt: Zum einen wurde das zu-Grunde-gehen eines Menschen an den aus seinen Ängsten erwachsenden Sünden und einer sich daraus ergebenden Entwicklung zur absoluten Boshaftigkeit demonstriert. Gerade die grausame Strafe, die dieser Mensch am Ende des Märchens zu erleiden hat, sorgt für eine abschreckende Wirkung und warnt die Rezipierenden davor, einen ähnlichen Weg einzuschlagen. Beachtlich ist, dass die Grausamkeit der Mutter/Stiefmutter wohl die angsteinflößendste Wirkung auf die Rezipierenden hat, die Figur der Königin im Märchen aber auch selbst die meiste Angst aussteht, da Angst grundsätzlich in ihrem Charakter 
angelegt ist. Sprachlich wird diese Angst der Königin überwiegend durch eine Beschreibung ihrer physischen Reaktionen vermittelt - ihr Erbleichen, der erhöhte Pulsschlag und ihre Unfähigkeit zur Sprache oder gar Bewegung stehen stellvertretend für die Furcht, die die Figur auszustehen hat. Durch einen solchen Rückgriff auf den Bereich körperlicher Reaktionen wird zugleich auf die Erfahrungswelt der Rezipierenden verwiesen und diesen ein Einfühlen in die angsteinflößenden Situationen ermöglicht. Zum anderen wird durch die Struktur Verbot - Überschreiten des Verbots - Strafe auf die Wichtigkeit der Einhaltung elterlicher und gesellschaftlicher Normen verwiesen und dies anhand der beängstigenden Konfrontationen zwischen der Königin und Schneewittchen dargestellt. Trotz eines klaren Gut-Böse Verhältnisses besitzt auch Schneewittchen kleinere Charakterfehler wie Gutgläubigkeit und Verführbarkeit, die es den Rezipierenden erlauben, aus dem Geschehenen zu lernen, wodurch das Märchen wiederum seine pädagogisch-didaktische Funktion realisieren kann für diese Funktion scheint das Einbringen von Angst und Schrecken in das Märchen unvermeidbar zu sein (vgl. Kaiste 2005: 47, 185). Schneewittchens unschuldiger Charakter führt jedoch nicht zu dauerhaften Ängsten, wie sie anhand der Königin veranschaulicht werden. Ihre Ängste zeigen sich eher situativ in den vielfältigen Angstsituationen, mit welchen sie im Verlauf der Geschichte konfrontiert wird und die sich durch typische Angstmotive wie dem bedrohlichen Wald, wilden Tieren oder dem Verlassen-Werden auszeichnen. In diese situativen Ängste können sich die Rezipierenden besonders gut hineinversetzen, da es sich um elementar menschliche Ängste handelt.

In der Disney-Version bleibt eine pädagogische Funktion weitgehend aus, indem die Königin sich nicht erst aufgrund von Ängsten und dem Verfall an Sünden zur Boshaftigkeit entwickelt, sondern sie als beinahe unmenschliches Feindbild von vorne herein etabliert ist. Dies dient dazu, den reinen, unschuldigen Charakter Schneewittchens als unfehlbar/idealisiert hervorzuheben. Auch sie erlebt situative Angst, allerdings in gemäßigter Form, vor allem wegen des gänzlichen Ausbleibens von Verführbarkeit oder Ungehorsam. Abgesehen davon, dass die Königin grausam genannt wird, wird auf Grausamkeitsdarstellungen wie das Verspeisen von Organen oder zu Tode tanzen weitestgehend verzichtet und zahlreiche potentiell angsteinflößende Szenen werden durch Euphemismen heruntergespielt. Letztendlich wird so in der Disney-Version weitaus weniger Angst ausgelöst, als im ursprünglichen Märchen der Gebrüder Grimm. 


\section{Fazit}

In diesem Beitrag wurden sowohl die sprachliche Konstruktion der Emotion Angst, als auch der mögliche pädagogische Nutzen einer solchen Angstdarstellung in verschiedenen Versionen des Märchens Schneewittchen untersucht. Dabei zeigt sich, dass die Textgattung des Märchens sich hervorragend für die Analyse einer solch grundlegenden Emotion eignet, da uns das Märchen ein „Welterleben“ präsentiert, welches wesentlich durch unsere Ängste mitgeprägt wird. Anhand eines Märchentextes lassen sich somit einerseits die Ängste der Figuren analysieren, diese spiegeln andererseits aber auch unsere eigenen Ängste als Rezipierende wider und lassen uns somit Rückschlüsse auf universelle Angstmotive ziehen. Auch im Märchen werden zur Verbalisierung der Emotion Angst Erlebens- und Emotionsbegriffe, Idiome und metaphorische Wendungen herangezogen. In „Schneewittchen“ spielt hier wiederum der Bereich der körperlichen Reaktionen eine herausragende Rolle - im Mittelpunkt steht dabei oft die Herzmetaphorik. So ist beispielsweise davon die Rede, dass sich ein Herz im Leibe herumkehrt, ein Stein vom Herzen gewälzt wird oder alles Blut zum Herzen fließt. Während Dobrovol'skij sich gesondert auf die Idiome der ,reinen' Angst und die zu deren Konzeptualisierung notwendigen Symptome und Begleiterscheinungen bezieht, hat es sich für meinen Beitrag und besonders für die Charakterisierung der Gegenspielerin Schneewittchens als geradezu essentiell ergeben, eine Mischung aus Angst und weiteren starken Emotionen in die Betrachtungen mit einzubeziehen, wobei ich davon ausgehe, dass die Angst als Ausgangs- und Basisemotion oftmals weitere ,Folgeemotionen' wie Zorn und Neid nach sich ziehen kann. Für meinen Beitrag konnte diesbezüglich häufiger die durch Kövecses postulierte Unterscheidung zwischen metonymischen und metaphorischen Bereichen der Angst herangezogen werden, welche Dobrovol'skij allerdings aufgrund ihrer wenig konsequenten Differenzierbarkeit kritisiert (Dobrovol'skij 1995: 327f.). Die Herzmetaphorik erlaubt es auch, die größten Unterschiede in der Darstellung der Mutter/Stiefmutter/bösen Königin herauszuarbeiten: In der Disney-Version ist die Angst der Königin weiteren Übeln wie Grausamkeit und Machtgier nebengeordnet - die Kontrahentin hat von Anfang an ein verdorbenes Herz. Die charakterlichen Übel der Mutter/Stiefmutter bei den Grimms entspringen hingegen geradezu aus ihrer Angst, welche bewirkt, dass Neid und Hochmut wie Unkraut aus ihrem Herzen wachsen. Hierzu machte schon Gerok-Reiter ähnliche Entdeckungen in ihrer Untersuchung mittelhochdeutscher Epik: Die Angst der dem Bereich des Bösen zugeordneten Charaktere verweist auf deren mangelndes Gottvertrauen und ihre Weltverfallenheit und macht sie anfällig für weitere sündhafte Charakterschwä- 
chen (Gerok-Reiter 2007: 133). Während die modernere Disney-Version an Grausamkeiten spart oder auf Euphemismen zurückgreift, um beängstigende Sachverhalte zu beschönigen, ist deren Wirkung auf die Rezipierenden deshalb nicht unbedingt ,kindgerechter.' Der Fokus auf die Idealisierung Schneewittchens verbaut einen lehrreichen, pädagogischen Effekt, indem weder Schneewittchen, noch der Königin Raum für eine Entwicklung gelassen wird. Stattdessen wird eine zu krasse Schwarz-Weiß-Zeichnung präsentiert, die selbst eine Identifikation mit der ,guten Seite' nur schwerlich zulässt. Die Angstdarstellung in den Grimm-Versionen hingegen hat einen warnenden und $\mathrm{zu}$ belehrenden Effekt und zeigt Schneewittchen - obwohl eine deutliche Polarisation stattfindet nicht als unfehlbaren Charakter. So können die Rezipierenden sowohl aus den Fehlern der Gegenspielerin, als auch aus Schneewittchens Fehlern lernen, wenn es zu einer Konfrontation seiner eigenen Lebensängste kommt.

\section{Literatur}

Bähr, Andreas (2013): Furcht und Furchtlosigkeit. Göttliche Gewalt und Selbstkonstitution im 17. Jahrhundert. Göttingen: V\&R unipress.

Becker, Maria (2016): Die Flüchtlingsdebatte in den Medien Deutschlands: eine korpus- und diskurslinguistische Untersuchung der Konzeptualisierung von Angst. Sprachreport 32, 1-11. [https://ids-pub.bsz-bw.de/frontdoor/index/index/docld/4967].

Bettelheim, Bruno (1977): Kinder brauchen Märchen. Stuttgart: Deutsche Verlags-Anstalt.

Braun, Martin (1985): Mythen in der Erziehung? - Vorschlag für eine Pädagogik der kleinen Wahrheiten. In: Christian Büttner (Hrsg.), Zauber, Magie und Rituale. Pädagogische Botschaften in Märchen und Mythen, 81-100. München: Kösel.

Crago, Hugh (2008): What Is a Fairy Tale? In: Andrea Schwenke Wyile \& Teya Rosenberg (Hrsg.), Considering Children's Literature. A Reader, 162-178. Ontario: Broadview Press.

Dettmering, Peter (1984): Angst im Märchen. In: Paul Götze (Hrsg.), Leitsymptom Angst, 159165. Berlin u. a.: Springer.

Dinzelbacher, Peter (1993): Ängste und Hoffnungen/Mittelalter. In: Peter Dinzelbacher (Hrsg.), Europäische Mentalitätsgeschichte. Hauptthemen in Einzeldarstellungen. 2. Auflage, 315345. Stuttgart: Alfred Kröner.

Disney, Walt (2018): Das große goldene Buch der Prinzessinnen. Hamburg: Carlsen.

Dobrovol'skij, Dimitrij (1995): Schiss und Espenlaub: Idiome der Angst. Folia linguistica 29/34, 317-346.

Endres, Rolf (1987): Vorbemerkungen zu einer Untersuchung des Feldes der „Angst“Ausdrücke in Otfrieds Evangelienbuch. In: Rolf Bergmann u. a. (Hrsg.), Althochdeutsch 2, 1000-1011. Heidelberg: Winter. 
Fiehler, Reinhard (2011): Wie kann man über Gefühle sprechen? Sprachliche Mittel zur Thematisierung von Erleben und Emotionen. In: Lisanne Ebert, Carola Gruber, Benjamin Meisnitzer \& Sabine Rettinger (Hrsg.), Emotionale Grenzgänge. Konzeptualisierungen von Liebe, Trauer und Angst in Sprache und Literatur, 17-33. Würzburg: Koenigshausen und Neumann.

Gerok-Reiter, Annette (2007): Die Angst des Helden und die Angst des Hörers. Stationen einer Umbewertung in mittelhochdeutscher Epik. Das Mittelalter 12/1, 127-143 [Themenheft Angst und Schrecken im Mittelalter. Ursachen, Funktionen, Bewältigungsstrategien. Hrsg. von Annette Gerok-Reiter und Sabine Obermaier unter Mitarbeit von Claudia Lauer].

Gerstl, Quirin (1964): Die Brüder Grimm als Erzieher. Pädagogische Analyse des Märchens. München: Ehrenwirth.

Götze, Paul (Hrsg.) (1984): Leitsymptom Angst. Berlin u. a.: Springer.

Grimm, Jacob \& Wilhelm Grimm (2000): Die schönsten Märchen der Gebrüder Grimm. Oldenburg: Lappan.

Gutter, Agnes (1968): Märchen und Märe. Psychologische Deutung und Pädagogische Wertung. Solothurn: Antonius.

Horn, Katalin (1990): Lebenshilfe aus „uralter Weisheit“? Psychologische und populärpsychologische Märchenrezeption unter ihrem therapeutischen Aspekt. In: Hans-Jörg Uther (Hrsg.), Märchen in unserer Zeit. Zu Erscheinungsforen eines populären Erzählgenres, 159-169. München: Eugen Diederichs.

Kaiste, Jaana (2005): Das eigensinnige Kind. Schrecken in pädagogischen Warnmärchen der Aufklärung und der Romantik. Akademische Abhandlung im Fach Germanistik zur Erlangung des Grades eines Doktor philosophiae. Uppsala: Universität Uppsala, Digital Publicing Centre.

Kövecses, Zoltán (1990): Emotion Concepts. New York u. a.: Springer.

Maier, Karl Ernst (1987): Jugendliteratur. Formen Inhalte pädagogische Bedeutung. Bad Heilbrunn: Julius Klinkhardt.

Nübling, Damaris, Antje Dammel, Janet Duke \& Renata Szczepaniak (2017): Historische Sprachwissenschaft des Deutschen. Eine Einführung in die Prinzipien des Sprachwandels.

5. Auflage. Tübingen: Narr.

Rölleke, Heinz (1986): Die Märchen der Brüder Grimm. München/Zürich: Artemis.

Scherf, Walter (1990): Funktion und Bedeutung der Kindermärchen heute. Strukturanalytische Betrachtungen zur mündlichen und domestizierten Überlieferung. In: Hans-Jörg Uther (Hrsg.), Märchen in unserer Zeit. Zu Erscheinungsformen eines populären Erzählgenres, 170-179. München: Eugen Diederichs.

Strehlow, Rosita (1985): Die Bedeutung der Grimmschen Märchen für die Erziehung von Kindern. Frankfurt a. M.: Haag und Herchen.

Trescher, Hans Georg (1985): Magie und Empathie. In Christian Büttner (Hrsg.), Zauber, Magie und Rituale. Pädagogische Botschaften in Märchen und Mythen, 43-66. München: Kösel. Whitley, David (2012): The Idea of Nature in Disney Animation. From Snow White to Wall-E. Surrey: Ashgate Publishing Limited. 